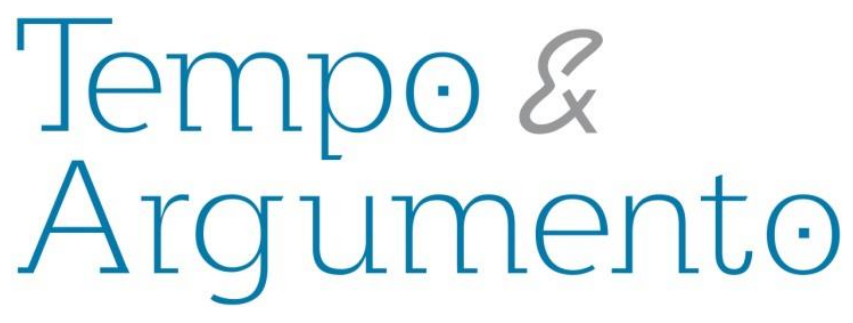

\title{
Narrativizaciones del yo: los impostores y la construcción del personaje-yo deseado en la sociedad digital
}

\begin{abstract}
Resumen
La sociedad digital permite la construcción de una o más identidades en sus múltiples espacios virtuales, lo que conlleva una narrativización del yo en todos esos ámbitos: el relato de lo propio como construcción de nuevas identidades y nuevas proyecciones de la identidad propia. Así pues, la construcción de la identidad a través del relato textual o audiovisual en internet ha permitido toda una nueva narrativa de la identidad que, por supuesto, tiene antecedentes en casos reales y en la tradición ficcional y en la frontera entre ambos mundos. Para entender el fenómeno contemporáneo, recorremos una serie de casos representativos y definitorios desde el punto de vista social e histórico en la esfera hispana e internacional con un foco especial en su impacto en la producción cultural contemporánea. Nuestro estudio aborda cómo estos impostores, sus herramientas y sus procedimientos se vinculan con los fenómenos actuales de representación del yo, tanto cuando son con vocación biográfica como ficcional.
\end{abstract}

Palabras clave: Sociedad digital; Impostura; Fingidor; Narrativa del yo; Identidad.

\section{Daniel Escandell Montiel}

Doctor en Literatura por la Universidad de Salamanca. Es autor del libro Escrituras para el siglo XXI. Literatura y blogosfera

(Iberoamericana-Vervuert)y coautor de El gabinete de Fausto. Teatros de la escritura y la lectura a un lado y otro de la frontera digital

(CSIC) junto a Fernando R. de la Flor. En la actualidad trabaja en el área de I+D+i de Cursos Internacionales de la Universidad de Salamanca. Fundador y director de la revista Caracteres. Estudios culturales y críticos de la esfera digital. España danielescandell@usal.es

\section{Para citar este artículo:}

ESCANDELL MONTIEL, Daniel. Narrativizaciones del yo: los impostores y la construcción del personaje-yo deseado en la sociedad digital. Tempo e Argumento, Florianópolis, v. 7, n.15, p. 71 102. maio/ago. 2015.

DOI: $\mathbf{1 0 . 5 9 6 5 / 2 1 7 5 1 8 0 3 0 7 1 5 2 0 1 5 0 7 1}$

http://dx.doi.org/10.5965/2175180307152015071 


\section{Narrativizations of the Self: the impostors and the construction of the desired character-self in digital society}

\begin{abstract}
A digital society enables the construction of one or more identities in its multiple virtual spaces, which entails a narrativization of the self in all those spheres: one's story as the creation of new identities and new projections of one's own identity. Therefore, the construction of this identity by means of a textual or audio-visual story in the Internet has facilitated a whole new narrative of identity, which, of course, has antecedents in real-life cases, in traditional narratives and in the border between both worlds. In order to understand the contemporary phenomenon, we cover a series of representative and defining cases from a social and a historical perspective within the Hispanic and international sphere, with a special emphasis on its impact on contemporary production. Our study addresses how these impostors, their instruments and their procedures are directly linked with current phenomena of the representation of the self, both with a biographic and fictional vocation.
\end{abstract}

Keywords: Digital society; Imposture; Faker; Selfnarrative; Identity.

\section{Narrativizações do eu: os impostores e a construção da personagem- eu desejada na sociedade digital}

\begin{abstract}
Resumo
A sociedade digital permite a construção de uma ou mais identidades nos seus múltiplos espaços virtuais, o que acarreta uma narrativização do eu em todos esses âmbitos: a narração do próprio como construção de novas identidades e novas projeções da identidade própria. Por isso mesmo, a construção da identidade através do relato textual ou audiovisual na Internet permitiu uma nova narrativa da identidade que, evidentemente, encontra os seus antecedentes em casos reais e na tradição ficcional e na fronteira entre estes mesmos mundos. Para compreender o fenómeno contemporâneo, percorremos uma série de casos representativos e definitórios do ponto de vista social e histórico na esfera hispânica e internacional com um enfoque especial no seu impacto na produção cultural contemporânea. O nosso estudo aborda a forma como estes impostores, as suas ferramentas e os seus procedimentos se vinculam com os fenómenos atuais de representação do eu, tanto com vocação biográfica como ficcional.
\end{abstract}

Palavras-chave: Sociedade digital; Impostura; Fingidor; Narrativa do eu; Identidade. 


\section{Presencias alteradas en la reciente historia sociocultural y su impacto en la ficción}

La volatilidad de la identidad ha sido explorada en la ficción a través de incontables novelas, series de televisión, películas, etc., a través de una multitud de géneros que van desde el género negro hasta el espionaje y, por supuesto, la ciencia ficción. Las estrategias de la suplantación, el robo de identidad y el control de los demás por su anulación * componen una interesante taxonomía de la ficción en relación a la identidad propia y ajena. Sin embargo, no deben obviarse los anclajes de la realidad y la tradición sociocultural de la alteración de la presencialidad, particularmente en la historia reciente, por su influencia lógica en los procesos creativos y predisposición en la recepción de las obras ficcionales. No en vano, tanto creadores como público están inmersos en la sociedad y no son ajenos al espíritu de los tiempos o Zeitgeist que viven, razón por la que hay una predisposición ante diferentes obras en diferentes tiempos. Naturalmente, las grandes obras universales lo son porque trascienden ese marco temporal y si entendemos al Tom Ripley de Patricia Highsmith es porque el personaje nos es próximo y, en este caso, porque su modo de ser otro, sus anhelos y objetivos, y su percepción del mundo no nos son ajenas.

Por esta razón, parece necesario realizar un recorrido ante algunos casos destacados de impostura, mascarada y narrativización del yo en la historia reciente. Nos centraremos especialmente —aunque no de forma excluyente- en los casos españoles que han tenido cierta trascendencia internacional durante el siglo XX como marco temporal que ha ayudado a constituir el Zeitgeist de la construcción social del yo alterado ya en la era de lo digital. Con esta orientación, resulta central el caso del agente Garbo, es decir, el espía español Joan Pujol García (1912-1988) que fue una de las más importantes piezas del entramado de espionaje aliado contra el ejército nazi en la II Guerra Mundial. Cuando Pujol no logró convencer a los británicos de que podría ser un eficiente espía a su servicio contra los alemanes, por propia iniciativa se postuló como agente doble a los nazis y les hizo creer que estaba en Londres cuando, en realidad, operaba desde Lisboa.

\footnotetext{
* El peso de los impostores en la ficción reciente y la cultura pop contemporánea, así como sus estrategias y taxonomía han sido expuestas de forma detallada en Escandell (2015).
} 
Los ingleses finalmente descubrieron que había logrado pasar información falsa a los alemanes convirtiéndose, de hecho, en una importante fuente de información; cuando ya contó con el amparo británico el agente Garbo fue uno de los responsables de hacer que el desembarco de Normandía tuviera éxito: su desinformación como parte de la Operación Fortitude respaldada por la confianza que los altos mandos tenían en él, logró que los nazis creyeran que la gran ofensiva tendría lugar en Calais ${ }^{\dagger}$. Si Garbo alcanzó tal credibilidad fue, en parte, porque los ingleses le indicaban qué información real podía dar y cuál era la desinformación que debía transmitir muy acertadamente (por supuesto), pero esto no habría sido posible sin la red de casi treinta contactos por todo el mundo que él construyó y que era completamente falsa. Esa treintena de personas eran solo diferentes personajes creados por él. Los vívidos relatos de una Londres en la que no había puesto el pie convencieron a los nazis de que tenían un espía en el corazón del enemigo y sus muchos contactos que le hacían de informador no existieron jamás.

Dada la importancia del conflicto de la II Guerra Mundial a la hora de construir la identidad occidental, el diseño sociopolítico de la Europa actual y su influencia en buena parte del mundo, tanto de forma directa como indirecta, consideramos importante señalar a otro importante fingidor español que se vincula con este duro periodo de la historia internacional. Se trata de Enric Marco (1921-), el cual convenció durante años a quien le escuchara de que había sido un superviviente de los campos de concentración nazi tras haber sido apresado como miembro de la Resistencia en Francia. Recibió, de hecho, múltiples reconocimientos, como la Creu de Sant Jordi (máxima distinción civil catalana), aunque cuando se destapó su engaño la devolvió (no sin que antes se especulara abiertamente sobre una retirada oficial). Marco, que incluso presidió la Associació Amical de Mauthausen i altres camps, fue desenmascarado por investigadores que desmontaron su relato como luchador antifranquista que huyó a Francia para combatir a los enemigos nazis al constatar que había emigrado como trabajador de la industria para Alemania bajo los programas del Ministerio de Asuntos Exteriores franquista. Se le descubrió poco antes de las conmemoraciones de Mauthausen, previstas

\footnotetext{
† Además de aparecer en un documental de 2009, Garbo: el espía, la historia de Joan Pujol se relata pormenorizadamente a través de los documentos de Tomás Harris en el libro Garbo: Doble agente (2000).
} 
para el 8 de mayo de 2005, y él reconoció su engaño, algo de lo que se hizo eco la prensa española poco después con titulares tan contundentes como "El presidente de los deportados españoles en Mauthausen confiesa que nunca fue preso de los nazis" (EFE, 2005). Para rizar el rizo, en 2009 se hizo un documental en el que él mismo contaba su experiencia real en Alemania pero quizá la parte más singular es que en los últimos tiempos ha surgido un perfil falso en Twitter <https://twitter.com/enricmarcobtlle> en el que se publican mensajes como "En estos momentos dificiles, mi apoyo a Ariel Sharon, luché a sus órdenes en el yom kippur junto a Yul Briner y Ben Afflec" (2-02-14). El caso de Marco fue de nuevo repopularizado a finales de 2014 y principios de 2015 con motivo de la publicación del libro El impostor (2014) de Javier Cercas. En esta novelización de los encuentros entre autor y fingidor y los relatos de este último, se expone de forma pormenorizada la doble vida de Marco: la real y la ficcional. En el texto, Cercas expone la narrativización extrema de la vida propio que creó Marco — como otros impostores-y le describe incluso como "el novelista de sí mismo" que sitúa en la línea de los quijotes a través del diálogo que mantiene con Santiago Fillol (uno de los directores del documental Ich Bin Enric Marco de 2009), a quien hace decir en sus páginas:

¿No te das cuenta? Todo en él es una ficción enorme, una ficción, además, incrustada en la realidad, encarnada en ella. Enric es igual que don Quijote: no se conformó con vivir una vida mediocre y quiso vivir una vida a lo grande; y, como no la tenía a su alcance, se la inventó. (CERCAS, 2014, p. 33)

Si nos permitimos dar el salto ya hasta los casos más próximos, en los primeros pasos de nuestro siglo XXI, resulta también inevitable pasar por Alicia Esteve (1973-). Esta española se hizo pasar por Tania Head con el objetivo ser una de las personas afectadas por los atentados del 11 de septiembre de 2001 en el World Trade Center de Nueva York.

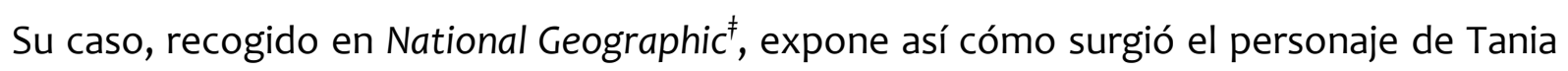
Head:

\footnotetext{
${ }^{\ddagger}$ Asimismo, además del reportaje que aquí citamos de forma directa, se creó un documental y se publicó un libro (FISHER y GUGLIELMO, 2012). El documental fue adaptado a versión reducida (mediometraje de 45 minutos) para su emisión —originalmente- a través de National Geographic, que ha sido emitido en múltiples países, entre ellos España, Rumanía, Alemania, etc., mediante cadenas de televisión
} 
Tras los atentados los atentados del $11 \mathrm{~S}$, aparece públicamente una persona altamente afectada por la tragedia, ella es Tania Head, una joven dentro de los 19 supervivientes que estaban en plantas superiores al lugar de la colisión en la torre Sur.

Tania, había estudiado en Harvard y Stanford, y trabajaba en la planta 78 de la torre Sur en Merrill Lynch, el lugar donde impactó el avión, que según ella, decapitó a su secretaria. En el momento del impacto se quedó inconsciente, y su brazo, empezó a arder. Habría perecido de no ser por la ayuda de un voluntario que, con la cara tapada con un pañuelo rojo, le apagó las llamas y la ayudo a salir.

En su huida, un hombre desconocido, en su lecho de muerte, le dio su anillo de bodas para que se lo entregase a su esposa, y Tania lo hizo en cuanto pudo.

Además de sufrir este calvario, Tania perdió a su prometido en la torre Norte, con el que iba a contraer matrimonio en pocos días.

Tras esto, Tania permaneció en el anonimato, posteando en las redes de supervivientes y creando un mito en torno a su persona, era la súper superviviente [...]. (2012)

Su caso fue destapado por periodistas del New York Times y su historia plantea una cuestión que consideramos relevante: ¿se convierte el fingidor en el personaje que ha creado? La disociación con la realidad (esto es, creer ser quien no se es) puede llegar a ser tan fuerte que la personalidad creada para el proceso de fingimiento camaleónico domine a la original hasta que, al final, se cree ser quien no se es:

Tania Head era en realidad una barcelonesa que se había graduado en una escuela de negocios en España después de la tragedia de las Torres, y en ese momento, nadie tenía conocimiento de que hubiese estado en Nueva York. Tras esto, se consultó a las universidades de Harvard y Stanford, en las cuales no tenían constancia de una alumna llamada Tania Head, ni los familiares y amigos de su prometido, ni en el hospital, ni en la empresa en la que trabajaba habían oído hablar de Tania Head. Ni de Tania ni de Alicia Esteve, su verdadero nombre.

Tras esto, ella desapareció, y volvió a Barcelona, y según algunas fuentes, sigue creyendo que fue una victima del terrorismo, es decir, que llegó un momento en el que dejó de interpretar un papel, pues ella pensaba que su mundo de ilusión era una realidad y vivía en ella. (NATIONAL GEOGRAPHIC, 2012)

nacionales. 
Si nos movemos en el mundo del cine como espacio de narración, resulta también relevante cómo ha sido adaptada al cine (aunque libremente) la historia del francés JeanClaude Romand (1954-) a través de La vida de nadie (2002). Su historia también inspiró la novela L'Adversaire (2000), de la que se hizo igualmente una película homónima (2002). Romand asesinó en 1993 a su esposa, sus dos hijos y sus padres tras haber ocultado durante dieciocho años su verdadera vida. Para familia, amigos, vecinos y todo su entorno, Romand era médico e investigador en la Organización Mundial de la Salud; en la realidad, no terminó jamás su formación universitaria y vivía gracias al dinero que iba estafando a sus allegados y otras personas: incluso vendió curas milagrosas contra el cáncer. El detonante de su crimen fue, según la investigación, que la red de mentiras que había tejido fingiendo ser otro Romand estaba a punto de caerse por completo y no pudo soportar la idea de ser descubierto. Estos casos se vincularán muy especialmente con las suplantaciones, fingimientos y conductas camaleónicas en internet, de las que hablaremos más adelante, cuando por fin expongamos el caso de Debbie, en EE. UU.

\section{Más allá del fingidor: aproximación al fantasma del doble en la cultura audiovisual contemporánea}

Sin abandonar completamente estas máscaras camaleónicas de los fingidores (y ahora ya alejándonos de los casos reales por los condicionantes de este fenómeno), resulta imprescindible abordar la visión de el otro que es yo como revisión actual del fenómeno folclórico del doppelgänger ${ }^{\S}$ que ha sido filtrado incluso como parte del canon de la ficción humorística. Como guiño directo a los grandes referentes televisivos del espionaje y la impostura tras máscaras (es decir, los maestros del disfraz de Mission: Impossible), Mel Brooks recurrió a la parodia de esta suplantación del rostro total en High Anxiety (1977). En ella, Richard H. Thorndyke (Mel Brooks) se encuentra cara a cara con su doble aparente en un ascensor: sus caminos se cruzan, el del auténtico y el del doble

\footnotetext{
$\S$ En el folclore germano, verse a uno mismo (es decir, encontrarse con su doppelgänger) es el augurio de la muerte propia. Si, en cambio, son otras personas (familiares, amigos, etc.) los que ven un doppelgänger ajeno, esta visión se asocia con la muerte o enfermedad de una tercera persona. Claude Lecouteux recoge la explicación que aportó August Strindberg en su libro Hadas, brujas y hombres lobo en la Edad Media. Historia del doble, de gran síntesis: "el que ve a su doble es que va a morir” (1999, p. 8).
} 
perfecto que pronto cometerá un crimen para inculparle. Es, más que nunca, el retrato fílmico del gemelo malvado y no tanto el augurio de la muerte para quien se encuentra consigo mismo, sino para los demás. Por supuesto, este doble es un asesino contratado para suplantar — con sus mismas ropas y una elaborada máscara — al doctor Thorndyke e implicarle en un crimen. Cuando el doppelgänger se encuentra casualmente, esto crea lógicas intrigas sobre la propia identidad y la identidad de ese extraño reflejo de uno mismo, tal y como le sucede a Tertuliano Máximo Afonso, el profesor de Historia protagonista de $O$ homem duplicado $(2002)^{* *}$, de José Saramago, quien se ve inmerso en dudas al descubrir la existencia de su doble (el actor António Claro, conocido artísticamente como Daniel Santa-Clara) al ver una película en la que este aparece:

Lo que más me confunde, pensaba con esfuerzo, no es tanto el hecho de que este tipo se me parezca, de que sea una copia más, un duplicado, podríamos decir, casos así no son infrecuentes, tenemos los gemelos, tenemos los sosias, las especies se repiten, el ser humano se repite, es la cabeza, es el tronco, son los brazos, son las piernas, y podría suceder, no tengo ninguna certeza, es sólo una posibilidad, que una alteración fortuita en un determinado cuadro genético tuviese como efecto un ser semejante a otro generado en un cuadro genético sin relación alguna con el primero, lo que me confunde no es tanto eso como saber que hace cinco años fui igual al que él era en ese momento, hasta bigote usábamos, y todavía más la posibilidad, qué digo, la probabilidad de que cinco años después, es decir, hoy, ahora mismo, a esta hora de la madrugada, la igualdad se mantenga. (2002, n.p.)

En la adaptación al cine de la novela, Enemy (2013), el extrañamiento resulta más brutal si cabe y consigue trasladarse con éxito al espectador, algo que se puede apreciar en ciertas reacciones viscerales en las secciones de comentarios de webs especializadas en cine o el hecho de que no tardaran en salir vídeos y artículos en blogs de exégetas de la obra. Su ambientación resulta densa, enrarecida, llena de tonos ocres y planos que no permiten que la escena respire para reforzar los elementos oníricos, cuando no fantasiosos, que abren y cierran la película. Si la novela tiene elementos kafkianos, en la adaptación al cine se suma una estética lynchiana. Si la única voz narradora del libro de Saramago es una estrategia de fusión y juego de espejos con el lector (¿son realmente

\footnotetext{
** Citamos la obra a través de la traducción al castellano realizada por Pilar del Río.
} 
dos personas o son dos partes de la misma persona?), la fotografía y el lenguaje cinematográfico son los lógicos recursos de Villeneuve en su cinta para jugar al despiste de la misma manera que lo hace el escritor a través del flujo de la narración y el diálogo con su singular prosa. Tertuliano y Antonio (o Adam y Anthony en la película) son la misma persona: en la novela el bucle se cierra cuando Tertuliano, asumiendo la vida e identidad de Antonio, recibe la llamada telefónica que no es sino el primer contacto que tuvo con su otro yo, con el actor, y el diálogo que sostuvieron se repite, ahora desde el otro lado: él es quien escucha al profesor de Historia. "Tertuliano Máximo Afonso se estremeció, en este mismo sillón estaría sentado Antonio Claro la noche en que le telefoneó. Ahora la conversación va a repetirse, el tiempo se arrepintió y volvió atrás" (2002: n.p.). En cuanto a la adaptación cinematográfica, el director reconoció que se planteó la película para que pudiera entenderse de ambas maneras: "Para que la película funcionara tenía que haber una tensión permanente entre la posibilidad de que haya dos hombres y la posibilidad de que haya solo uno. Funciona de las dos maneras para que el espectador no pueda decantarse" (citado por PRIETO, 2014). En este caso, el doppelgänger no es tal, sino el resultado de una psicosis, de la incapacidad del personaje principal de afrontar su vida y sus relaciones con las mujeres, por lo que aunque se juega con la suplantación por el doppelgänger durante toda la historia, este es él mismo.

El relato tiene paralelismos evidentes con Двойник (El doble) (1846), la segunda novela de Fiódor Dostoievski, de muy patente influencia gogoliana, no solo por la introducción de lo fantástico, sino por la impostura y la máscara social como vía de conducta. Quizá la acogida de esta obra no fue la que se habría esperado en un primer momento, pero sí ha resultado influyente a largo plazo y como referente en la tipología del doppelgänger. Se adaptó (libremente) al cine en 2013 con The Double, cinta escrita y dirigida por Richard Ayoade en la que el introvertido y poco decidido Simon James (Jesse Eisenberg) se ve sorprendido cuando aparece en el trabajo el dominante y extrovertido James Simon (Jesse Eisenberg). Aunque sus compañeros parecen no observar que son idénticos, sí los confunden entre sí, particularmente cuando Simon adopta una actitud más agresiva y decidida como la que muestra James. Cuando la exposición a Simon/James no es real, sino mediada — por ejemplo, a través de fotografías— la confusión es plena: la 
personalidad es quien marca quién es cada uno, pero cuando se retrata la realidad distanciada, mediada, la confusión y la ambivalencia son plenas:

-Hans, have you spoken to the new employee?

-James? Yeah sure, I met him.

-And?

- He seems all right.

—But did you notice anything strange about him? I mean, did he remind you of anyone?

-No.

-No one at the office?

-No.

Cuando Simon no puede más se enfrenta a James en el trabajo, ante los jefes, gritándole que le ha robado la cara. En una sociedad burocratizada al extremo como la presenta la película, Simon no existe porque está fuera del sistema al perder su identificación y no pueden darle una nueva identificación porque no está en el sistema. No estar en el sistema es no existir y la anulación plena de Simon llega cuando siente que James ha conquistado todos los planos de producción de presencia: ha seducido (entre otras muchas) a la chica que quiere, se ha apropiado de sus ideas para progresar en la empresa y se ha ganado el favor y la estima de los compañeros de trabajo. Es un líder nato, despiadado y cínico, frente al cándido Simon. La solución para Simon en una sociedad desnaturalizada como esta es el suicidio, algo que se nos ha dicho al principio de la historia que es más que frecuente. La nota suicida que escribe es elocuente: "To Whom It May Concern: I have decided to end my life because I no longer exist. A person should amount to something and not float around this earth like a ghost". Texto que luego tacha para escribir una nueva nota de suicidio en la que leemos: "To Whom It May Concern: I am a ghost". El doppelgänger se apropia efectivamente de la existencia de Simon. Su presencia es la del reverso agresivo, liberado de condicionantes, que tantas veces se ha visto en las narraciones inspiradas en fenómenos disociativos de la personalidad. Suicidarse es matar también al doble y la muerte del duplicante es la única salida posible. Las cuestiones abiertas de la película son las mismas que en la novela, pues no se pretende responder si el protagonista (lákov Petróvich Goliadkin en el texto, Simon James en la pantalla) sufre alucinaciones, algún tipo de esquizofrenia o paranoia o si se está ante una suplantación de tipo sobrenatural (en un mundo tan burocratizado que la 
descarta por imposible). La novela permite más capas de ambigüedad, por supuesto, dado que su escritura permite que nos planteemos incluso si solo Goliadkin ve a su doble, Goliadkin menor, y en tal caso si la locura está en él desde el principio, o si va surgiendo progresivamente, incluso como fruto de una conspiración en su contra. La máscara y la suplantación son preocupaciones mayores de Goliadkin y es ahí donde se ha señalado en especial la influencia gogoliana en esta obra de Dostoievski. No hay un doble en la medida en que nadie es el doble de nadie, sino multiplicaciones que se vertebran y entrecruzan.

Enfrentarse al doppelgänger es el encuentro definitivo ante la verdad propia: se presenta mayoritariamente como el retrato fragmentado de la persona que no queremos ver que somos y su inclusión en la construcción las narrativizaciones del yo está fuertemente vinculada —más cuanto más nos sumergimos en la fantasía y nos alejamos del costumbrismo y los retratos realistas o hiperrealistas- a la observación atenta ante el espejo de un desconocido con el que lo compartimos todo externamente pero que, al presentarse desde la otredad, nos desvela el otro lado de la identidad que no vemos porque queda en el lado oscuro de la Luna de la psique de cada uno.

\section{La cultura de ser otros: su impacto en la sociedad digital y la narrativización del yo en el marco social de internet}

En los primeros apartados nos hemos centrado en realizar una somera cartografía del fingidor camaleónico como negación del yo (un yo que quiere ser otro) y en la confrontación con el otro yo a través del doble (el otro que quiere ser yo que es también el yo que el yo se niega) mediante ejemplos reales y ficcionales contemporáneos con especial relevancia en la construcción de la cultura de masas actual en la esfera social. Se trata, ante todo, de representaciones que o han sido populares en la ficción de consumo general (aunque, por su temática, suelen caer en realidad en la etiqueta de culto) o bien han ocupado una gran cantidad de páginas en la prensa y minutos en los noticieros de la televisión.

La sociedad digital crea una cultura de ser otros, primero porque lo permite con facilidad gracias a sus recursos tecnológicos y a la utilización de las pantallas como espejos deformantes y segundo porque hay una tradición de la encarnación de la 
otredad, del extrañamiento, del deseo de ser quien no se es y de controlar a quien no se puede controlar que las últimas décadas de obras de ficción reflejan solo como resultado de una preocupación humana que es parte de una extensa y antigua tradición presente en nuestras culturas.

En cierto sentido, si hay personas que aprovechan los recursos digitales para construir otras identidades y hacerse pasar por quienes no son, o dejar ver partes de quienes son que en otras circunstancias se mantendrían escondidas, es porque hay una cultura de la banalización en línea con los idearios del considerado posmodernismo, pero también de la transmodernidad en la que confluyen las tradiciones de lo clásico y lo moderno. Hay un cierto nihilismo y relativismo ( $y$, por tanto, una posición de enfrentamiento con lo transmoderno) en la conducta digital, lo que se percibe en conductas respaldadas en no pocas ocasiones por la banalización completa de la enfermedad mental para justificar jocosamente cualquier tipo de conducta. Por ejemplo, resulta fácil encontrar a personas que justifican determinados comportamientos clasificándose a sí mismos como enfermos afectados por el síndrome obsesivo compulsivo, lo que explica la proliferación de artículos explicando realmente qué es ese síndrome y qué sufren las personas que lo padecen. Se trata de una hipérbole continuada en el autorretrato como parte esencial del mundo digital que parece pretender la justificación de cualquier conducta en la red.

En una sociedad extremadamente medicalizada y arrastrada a una visión autopatológica de sí misma y del mundo, no es extraño que eso permee las actitudes en la red. Así vemos personas que se atribuyen la etiqueta de esquizofrénicos, paranoides, límites, narcisistas y un largo etcétera de serias patologías y trastornos de la personalidad solo porque reconocen en ellos mismos patrones que pueden identificarse parcialmente con el retrato ficcional (pues asumiremos que la mayoría no cuentan con formación especializada en psiquiatría) que se ha creado de esas enfermedades en los medios artísticos narrativos.

La presunción que debe asumirse es que la mayoría de la gente entra en unos parámetros de normalidad estandarizados y que no serían considerados enfermos mentales, algo que incluso los misántropos más convencidos podrían aceptar como 
válido. Por esta misma razón, aunque en no pocas ocasiones la ficción haya retratado a las personas con desórdenes disociativos de la personalidad a través de algunas de las novelas, películas o series que hemos recogido en páginas anteriores, eso no significa que una persona que utilice las mismas herramientas o algunas similares en internet (o un videojuego o mundo sintético determinado) padezca ese desorden. Dicho de otra manera, una persona que se comporta de forma diferente según el foro en el que esté navegando, cada uno con un avatar específico, no es una psicótica ni debería (seguramente) ser considerada como tal, pues se trata de un patrón de conducta fácilmente observable en el día a día: la gente se comporta de maneras diferentes según la compañía que tenga en cada momento (sin ir más lejos, qué y cuánto alcohol bebe un joven dependerá en buena medida de si está con amigos, con su familia, de la hora del día y del día de la semana) y nadie es igual solo que con otras personas. La personalidad es, en su estado natural, compleja, poliédrica (de hecho, podría considerarse incluso un polícoro, pues no solo debe considerarse una profundidad de carácter en un momento concreto y determinado, sino también a lo largo del tiempo) y el comportamiento social conlleva casi necesariamente la selección de qué lados mostrar. La sociedad digital es fiel reflejo de esto mismo añadiéndose las características necesarias de identificación (el avatar) y las posibilidades de aislamiento en comunidades diferentes no necesariamente conectadas entre sí y del uso de máscaras para marcar un distanciamiento afectivo.

Quizá por todo esto resultan especialmente interesantes las conductas extremas, algunas de las cuales han sido señaladas en páginas anteriores y que en varias ocasiones han Ilamado tanto la atención que han terminado siendo registradas extensamente en investigaciones e incluso obras documentales. El caso de Frédéric Bourdin fue recogido en la película documental The Imposter (2012) y tuvo un notable impacto mediático en la sociedad estadounidense en 1997. Bourdin, que entonces contaba 23 años, se hizo pasar por Nicholas Barclay, el hijo desaparecido en 1994 de una familia de clase trabajadora de Texas, pese a que Nicholas hubiera tenido entonces unos 17 años y era rubio y de ojos azules, mientras que Bourdin era moreno con ojos oscuros. Esta situación extrema fue el resultado de una red de mentiras en las que él mismo se sumergió como parte de un modus operandi de simulación de ser otras personas: Bourdin era un talentoso Ripley 
europeo que había sido ya fichado por la Interpol por hacerse pasar por menor de edad y recorrer Europa fingiendo ser otras personas. "From as long as I remember, I wanted to be someone else. Someone who was aceptable", admite Bourdin en las entrevistas que se ofrecen a lo largo del documental, lo que nos permite acercarnos a la condición psicológica que le llevó a perseguir ese medio de vida antes de acabar en prisión y posteriormente asentarse de nuevo en Francia y establecer una familia. De hecho, él mismo explica (aunque no entra en ningún momento en grandes detalles) que no se sentía amado en su familia, y que su origen (el padre era argelino y la madre tenía 17 años cuando lo tuvo) era foco de conflicto con su abuelo, al que retrata como un xenófobo convencido. Un fuerte impulso afectivo que, según varias personas que han tenido trato con Enric Marco, puede ser su motivación principal.

El paso a ser Nicholas, sin embargo, representaba un salto importante con respecto a sus intentos de no ser él mismo, pues no es lo mismo fingir ser otra persona que usurpar la identidad de un tercero. "I wasn't pretending no more [sic] to have another identity. I stole one”. El fingidor camaleónico se había convertido en un ladrón de cuerpos al asumir la identidad de un chico desaparecido y de destino incierto: la vida fingida ya no es una narración que le es externa, sino el relato propio de su vida. Se arrancan las páginas de su vida y el libro de su existencia se encuaderna con nuevas páginas para seguir escribiéndose en la nueva dirección.

Para justificar los años de desaparición, su reaparición en Linares (España), el acento extranjero y elementos estéticos, como el cambio en el color de los ojos, inventó toda una trama de secuestros de niños para sumergirlos en una red itinerante e internacional de pederastas controlada por altos mandos militares. Si la historia de la reaparición del desaparecido Nicholas ya se había hecho hueco en las noticias, el tormento del joven logró sumar todavía más horas de televisión. “I wanted the media's attention, so that I would make Nicholas even more real, that people would really believe that I'm Nicholas and they would love me even more for that". La ambición de este Ripley de carne y hueso no residía en el dinero, sino en el afecto: eso es lo que ansiaba y perseguía dejando de ser él para ser otras personas. Esta necesidad de negarse a sí 
mismo le permitió dotarse de las estrategias necesarias para convencer a los demás de que era quien decía ser.

Aunque los hechos tuvieron lugar en la segunda mitad de los años noventa, ya casi a las puertas del año 2000, los recursos y estrategias de Bourdin fueron esencialmente analógicos. No rastreó en Google a un niño desaparecido que pudiera suplantar, sino que esa necesidad llegó de manera un tanto inesperada y usó los recursos que le eran posibles entonces: llamó a comisarías estadounidenses haciéndose pasar por un policía español que había encontrado a un joven de ese país desorientado por las calles del sur del país europeo, hasta que consiguió dar con la tecla adecuada.

Las motivaciones que llevaron a la familia a aceptar a Bourdin como su desaparecido Nicholas no están claras. Aunque el suplantador asegura todavía sospechar que al menos parte de la familia sabe cuál fue el destino real del joven Nicholas y que tener a un Nicholas de vuelta alejaba los fantasmas del pasado, no es menos cierto que el dolor de una familia que anhela a cualquier precio recuperar al benjamín puede favorecer el autoengaño y querer ignorar todos los elementos incoherentes de lo sucedido, como el acento francés o el cambio de color de los ojos. Creen porque pueden y porque quieren creer que quien llama a su puerta es el hijo pródigo.

Lo contrario pasó con la familia de la gran duquesa Anastasia Nikoláyevna Románova, la hija más joven de Nicolás II, último zar de la Rusia Imperial y que fue asesinada el 17 de julio de 1918 junto a su familia directa. No han faltado las impostoras que pretendieron hacerse pasar por ella; quizá la más popular fue Anna Anderson, oriunda de Prusia Occidental (en la actual Polonia). Esta mujer, que había sido internada en un centro psiquiátrico alemán tras un intento de suicidio y que era conocida como Fräulein Unbekannt (señorita desconocida), terminó pretendiendo ser quien no era e incluso alcanzó cierta notoriedad y apoyos. Se demostró que era en realidad Franziska Schanzkowska y que tenía un extenso historial psiquiátrico. Su vida acabó llevándola a EE. UU., donde adoptó finalmente el nombre de Anna Anderson, aparentemente para huir de la prensa por la fama que había alcanzado en su intento de engaño. La familia directa, en cualquier caso, nunca la aceptó —ni a ella ni a otras impostoras- como Anastasia y el 
hermano de la fallecida, Ernesto Luis de Hesse-Darmstadt, el gran duque de Hesse, fue uno de los más implicados en desenmascarar a la impostora.

En la sociedad digital las múltiples identidades están a la orden del día, como hemos visto en páginas anteriores: es la sociedad petersburguesa de Gógol llevada al extremo. La impostura es necesaria para preservar la armonía social: no se miente en tanto en cuanto no son actos insinceros, sino socialmente convenientes asumidos como comunes. El retrato que se ofrece de esta fragmentación de la identidad en el documental Catfish (2010) resulta relevador. No vamos a valorar si esta producción, como el programa de televisión que inspiró y que ha producido la MTV bajo el nombre Catfish: The TV Show (estrenado en 2012 y con una cuarta temporada aprobada por la compañía), es un documental auténtico o un mockumentary (falso documental) ${ }^{\dagger}$. Al fin y al cabo, toda telerrealidad es la narración de una realidad que, si no es falsa per se lo es al narrativizarse: resulta ser fruto de una espectacularización del circunmundo que redefine qué es real y cómo se origina esta realidad, además de dictar nuevas claves de interpretación social sobre cómo se puede reaccionar ante esta realidad. La narrativización convierte lo grabado-emitido (en el mejor de los casos) en una versión deformada, avatarizada, de sí mismo que nosotros, como receptores, nos creemos porque queremos, porque dejamos la incredulidad junto al mando a distancia, en ocasiones en los huecos del sofá, del mismo modo que podemos aceptar narraciones, simulaciones e imposturas tras la pantalla del ordenador. Realizan el ejercicio de auto(r)ficción hasta tal punto que ellos mismos pueden obviar que están ante un pacto ficcional y no autobiográfico para convencerse de que no hay ya inscripción del autor como elemento generador de ficciones sino como hacedor de realidad.

En el documental de 2010 se nos presenta a un grupo de jóvenes que decide empezar a grabar el progreso de una relación sentimental incipiente que se ha formado a través de internet y que se ha mantenido estrictamente en los límites de la digitalidad, sin

\footnotetext{
" Casi desde el momento de su estreno se plantearon dudas sobre la autenticidad. Algunos críticos han asegurado que han constatado la veracidad de los hechos narrados y la identidad de quienes aparecen en el documental (EBERT, 2010); otros, por su parte, han apuntado que hay fragmentos reconstruidos (es decir, que no se grabaron en directo, sino que se reinterpretaron posteriormente), elementos que resultan inverosímiles (con un completo análisis crítico de la cinta y del rastro digital de los autores en su blog) y que podría haber un fuerte componente de dramatización para conseguir una historia mucho más atractiva (HUTCHESON, 2010).
} 
ningún tipo de encuentro físico. Es más, dentro del espectro de lo digital no se ha recurrido, por ejemplo, a la videoconferencia o a otros recursos del contacto en directo entre personas. Se centran en la figura de Nev Schulman y su relación con Megan, pero pronto descubren que las canciones que le manda en formato MP3 y que supuestamente canta ella están extraídas de vídeos de YouTube, lo que parece detonar la necesidad de saber qué está sucediendo realmente. Así que se desplazan hasta el pueblo de Ishpeming, en Michigan, donde vive Megan. No tardan en descubrir que muchas de las cosas que saben sobre Megan no son ciertas. La relación empezó cuando Abby, la hermanastra de Megan, le envió un dibujo; la pequeña Abby, de ocho años, es una pequeña celebridad artística local y pronto entabla amistad con Nev, lo que abre las puertas al contacto con su madre, Angela, y finalmente con Megan, que reside en Gladstone, también en Michigan. Pero Abby no es tampoco una niña prodigio con los pinceles.

Toda la mascarada se cae al poco de presentarse Nev, su hermano Ariel y el compañero Henry Joost en el pueblo. Aunque se dan todavía esfuerzos por mantener la ficción creada en internet, todo es resultado de Angela: ella es la que pinta, finge ser Megan y acumula múltiples perfiles falsos en Facebook para respaldar las ficciones creadas en torno a Abby y Megan. Megan es en realidad una persona construida en Facebook a partir de la imagen de una modelo y fotógrafa, Aimee Gonzales, residente en Vancouver.

Percibimos en Angela ciertos anhelos no realizados. Angela abandonó el que considera su sueño, pintar, para casarse con Vince y cuidar de sus dos hijos, que requieren atención continuada por sus discapacidades. A Vince le contaba que Nev en realidad le compraba los cuadros que pintaba, por lo que el engaño de Angela iba en las dos direcciones. Según explica, lo hizo "to have a good time. So, a lot of the personalities that came out were just fragments of myself. Fragments of things I used to be; wanted to be; never could be". La realidad de Angela en la red, construida a través de perfiles falsos o versiones ficcionalizadas de personas reales, era la de una mujer con una hija pequeña dotada para el arte, una atractiva hija mayor de 19 años dedicada a la veterinaria y un hijo músico. La realidad de Angela fuera de la red era bien diferente. 
Se teje, por tanto, una serie de mentiras que orbitan alrededor de personas irreales que ayudan a crear una fantasía para Angela, un mundo (el de Facebook) en el que no debe lidiar con el día a día de fuera de la pantalla. Con todo, el retrato final de Angela no es negativo; Vince, el marido, realiza un pequeño discurso en el que la presenta como un revulsivo para otras personas comparándola con un bagre en los siguientes términos:

They used to tank cod from Alaska all the way to China. They'd keep them in vats in the ship. By the time the codfish reached China, the flesh was mush and tasteless. So this guy came up with the idea that if you put these cods in these big vats, put some catfish in with them and the catfish will keep the cod agile. And there are those people who are catfish in life. And they keep you on your toes. They keep you guessing, they keep you thinking, they keep you fresh. And I thank God for the catfish because we would be droll, boring and dull if we didn't have somebody nipping at our fin.

La necesidad o recurso de olvidarse de ser uno mismo es el mismo en el que se basan las ficciones en las que el personaje crea toda una nueva identidad para superar un trauma. Es, en cierto sentido, una visión romántica y notablemente mediada de un trastorno de identidad disociativo. Esos casos extremos de la ficción como la Alice Gould de Los renglones torcidos de Dios de Luca de Tena (1979), el Edward Daniels de Shutter Island de Lehane (2003) o el Ripley de toda la saga de Highsmith nacido en 1955 no distan quizá tanto en sus dañadas almas de la Angela retratada en Catfish o de Bourdin: rotas en fragmentos que se reorganizan y buscan refugio en la red, donde es más fácil construir la narración de la vida propia, la apropiada o la imaginada.

En el caso de Catfish: The TV Show, una de las muchas producciones de MTV (antaño cadena centrada en la música) que se basan en cualquier aspecto de la telerrealidad, se ha señalado que en muchas ocasiones quien contacta con el programa no es el engañado (LUTES, 2013), sino la persona que estaba fingiendo ser otra en internet. $Y$ es que el programa presenta a parejas que se conocen solo por internet ante la sospecha de una de las partes de que la otra no es quien dice ser en realidad. Schulman, uno de los directores del documental Catfish y responsable del programa de televisión, explica que: 
Whether or not two people are totally lying to each other and it turns out to be a huge disaster, that's only the first part of the story. We then want to know why they are doing it, who they are, what they are feeling, what led them to this place, and why that resonates with thousands of other young people who have the same feelings, who don't have someone to talk to or don't know how to express themselves. (Citado por PORTER, 2012)

Sin embargo, el hecho de que sean mayoritariamente los fingidores los que contactan con el programa y no quienes están siendo engañados, de acuerdo a la investigación sobre la producción del programa realizada por Alicia Lutes en 2013, parece vincular ese tipo de conductas a la pulsión exhibicionista que mostró Bourdin: la necesidad de recibir una atención externa, mediática, para sentirse más queridos; quizá no siempre como sus personajes, sino también como ellos mismos. Se juntarían, así, dos pulsiones: por un lado, la de alcanzar la fama warholiana y, por tanto, pasajera (en estos casos, sin importar tampoco si esta está vinculada a productos de entretenimiento escasamente meritorios); por otro, la de cubrir necesidades afectivas y de atención. Por supuesto, resulta fácil confundirlas entre sí e incluso podemos decir que una es la consecuencia directa de la otra en una sociedad espectacularizada y constantemente mediada por pantallas y retratos deformados de la realidad a través de la sala de montaje.

\section{La espectacularización del yo: ficcionalización de la vida propia}

La espectacularización es dominante en contextos sociales primados por lo hedonista, lo extimista y lo egotista, donde el culto ya no solo a la imagen sino al yo y, por tanto, a la representación de lo vivido (DÉBORD, 1967, p. 8) y no a lo vivido en sí mismo. La espectacularización es la narración, la ficcionalización y la revisión sesgada de lo experimentado para construir una memoria colectiva impostada del individuo. La suma de sus recuerdos públicos ha de ser la mediada, que permite marcar una distancia y controlar cómo va a ser recibida por los demás. Se construye un relato de lo propio y cada vida es (casi) autoficción en la medida en que es redirigida y supervisada en su capa de exhibición pública. El modelo de conducta de redibujado de la realidad a través de la (supuesta) realidad ficcionalizada como resultado de la grabación/guionización de la 
(supuesta) realidad proyectada en medios de comunicación fue descrito ya por Janet Maslin en una elocuente cita que recuperó David Foster Wallace en su ensayo "E Unibus Pluram":

We may be hearing about "real life" only on television shows made up of fifteen-second sound bites (in which "real people" not only speak in brief, neat truisms but actually seem to think that way, perhaps as a result of having watched too much reality-molding television themselves). (Citado por WALLACE, 1993, n.p.)

La influencia de la percepción de la realidad en la dimensionalización, conceptualización y expresión de la propia experiencia vital (esto es, el qué y el cómo de cada uno) se define por lo visto. La imitación como clave sempiterna del aprendizaje permite la capa de influencia de la realidad deformada percibida a través de los medios, por lo que no solo se actúa como el modelo de conducta recibido sino que eso se asume como verosímil, pese a ser un mundo de ficción o una realidad ficcionalizada. Se es (o se aspira a ser) como se ve que los demás son y eso influye también en la construcción de los relatos de la propia existencia, es decir, en la ficcionalización que emitimos de nosotros mismos hacia los demás.

Desde luego, siempre se ha controlado qué se comparte con los demás y las convenciones sociales de persecución del éxito y negación del fracaso han dictado una neutralidad y negación del error y lo que no sea animosamente positivo. Incluso en aquellas sociedades quizá más dadas al rencor y a la animadversión hacia el éxito se han visto ya conquistadas en buena medida por las seudofilosofías del éxito individual como desviación (todavía más) perversa de la desviación del concepto a veces identificado como sueño americano que deja de lado la igualdad de oportunidades para ser llana adoración del capitalismo exacerbado (aquel vinculado a los anarcocapitalismos) y que autores, como Barlett y Steele (2012), atribuyen, de hecho, al fracaso de este sueño, secuestrado por fenómenos de apropiacionismo por las grandes corporaciones.

La identidad digital es una cámara de lente plenóptica, con capacidad de captar y ofrecer una información de gran profundidad de campo para reenfocar y desenfocar posteriormente a voluntad porque la información de imagen capturada es, en sí misma, multiperspectiva. En el foco de atención pueden ponerse entidades fragmentarias o 
completamente impostadas y eso crea también un componente afectivo que puede estar orientado no a uno mismo, sino también a otros. Un ejemplo de esto fue el protagonizado por Kaycee Nicole Swenson, una moribunda adolescente estadounidense que se hizo popular por un blog, Living Colours. Kaycee no existió jamás, pero la comunidad digital llegó a llorar por su fallecimiento.

En 1998 la hija de una ama de casa estadounidense, en Kansas, creó junto a un grupo de amigos un perfil falso en una web social popular en esos años, College Club (actualmente, Teen.com). La cosa no fue a más hasta que un año más tarde su madre, Debbie, descubrió este perfil y decidió darle vida: definió al personaje como una joven deportista enferma de leucemia y se dejó querer por la comunidad en línea construyendo un círculo de amistades virtuales cada vez mayor. En 2000 debutó su blog, inaugurado gracias a la colaboración del engañado Randall Van der Woning e incluso fue entrevistada en el New York Times el 10 de agosto de 2000. Era una pequeña celebridad digital, un ejemplo de fortaleza ante una dura enfermedad, que no existía: solo era Debbie tras la máscara de la adolescente Kaycee. Un año más tarde Hafner publicó en el mismo New York Times un artículo explicando cómo había sido todo el proceso de engaño y cómo se había descubierto tras la muerte del personaje, gracias en buena medida al propio Van der Woning, a quien Debbie confesó todo el engaño. Pero no al principio: se había aferrado con una fuerza inusitada al personaje creado.

Fue el 19 de mayo cuando Debbie Swenson contactó telefónicamente con Randall y le confesó que Kaycee no era su hija biológica, sino una hija adoptiva y le pidió que no desvelara esta información. Sin embargo, al no hacerlo, la comunidad de usuarios de internet siguió investigando y se descubrió que eso era también mentira. La confesión real en la que Debbie admitió que absolutamente todo había sido falso tuvo lugar el 20 de mayo de 2001: Randall fue quien publicó en el blog Living Colours el mensaje público confirmando que Kaycee Nicole no había existido jamás. Debbie se defendió alegando que el personaje estaba basado en tres personas diferentes que había conocido y que habían muerto por diferentes tipos de cáncer. El caso fue investigado por el FBI, pero desestimado poco después ya que se estimó que, en cualquier caso, los beneficios económicos que habría obtenido Debbie Swenson eran inferiores a 1000 dólares y, por 
tanto, no constituyentes de delito para ese tipo de posible estafa de acuerdo a la legislación vigente entonces. Kaycee es una marioneta cuyos hilos mueve Debbie, una personalidad creada desde cero: Debbie no ha robado un cuerpo (una cuenta) ${ }^{\#}$, ni ha construido un autómata (un bot), pero sí una máscara con la que se disfraza: ella misma es camaleónica cuando asume la identidad de Kaycee.

¿Respondía esta proyección avatárica a una voluntad creativa con intencionalidad fictiva o había algún tipo de proceso disociativo en su personalidad? Había, sin duda, un acto performativo en esta constitución de un personaje por parte de Debbie para canalizar sus relaciones sociales. Quizá incluso un anhelo afectivo no resuelto que encontró una vía de escape a través de su avatar. En cualquier caso, fue una farsa mediada por las herramientas digitales que engañó a muchas personas, un fenómeno de enmascaramiento en el que se creó un personaje, un avatar, a través del cual podía actuar Debbie. Una fuerza demiúrgica de impostura para ser quien no se es.

Si regresamos a la ficción, podemos encontrar una alegoría de esa fuerza demiúrgica en las experiencias que sufre Nikki/Susan (Laura Dern) en la película Inland Empire (2006). La cinta se abre con una singular negación del rostro, con las caras desenfocadas de los personajes que hablan en polaco, como los rostros encubiertos de las noticias que intentan proteger la identidad de alguna persona en particular. En esta película de David Lynch, la actriz Nikki va asimilando a su personaje de ficción, Susan, y su mundo se hace cada vez más surrealista. Se descomponen los términos de la realidad, pero parece que no solo para ella. "Look at me and tell me if you've seen me before" es algo que, con variaciones - como un leitmotiv- se repite en no pocas ocasiones. Predomina, por supuesto, la atmósfera peculiar y los recursos oníricos propios del cine de David Lynch, pero la descomposición de la identidad del personaje que interpreta Laura Dern es la descomposición también de la realidad e incluso de la linealidad temporal, una exploración de la experiencia disociativa que se relaciona igualmente con otras películas del director, como Lost Highway.

\footnotetext{
\# Aunque emplea la imagen de una chica que ya había sido escogida antes de que encontrara el perfil de Kaycee el objetivo no es suplantar a esa chica. La fotografía se emplea como máscara, como referente visual, no como parte de una usurpación de la personalidad ni de los espacios de producción de presencia de la chica auténtica.
} 
Puede resultar también ilustrativo el breve caso que experimentó el poeta Ben Clark. El 24 de septiembre publicó en Facebook el siguiente mensaje: “Hay un tal Diego Orquida que usa mis fotos en su perfil. No sé quién es ni lo que quiere, pero si me hicieran el favor de encontrarlo y matarlo, les estaría muy agradecido", lo que abrió la pista. Efectivamente, si buscábamos en la red social ese nombre nos encontrábamos un perfil que empleaba las fotos de Clark en todos los apartados de inscripción visual de la identidad.

Este Orquida, una suerte de doppelgänger a medio cocer por su responsable. No ofrecía un perfil abierto que permitiera saber si estaba suplantando a Clark más allá de la usurpación de su rostro como rasgo identificador máximo. Ni el nombre, ni la información biográfica disponible, apuntaban en ese sentido. $\mathrm{Y}$, sin embargo, hubo algo suficientemente perturbador en esa acción como para motivar la reacción de Clark, el robo de algo importante que nos puede hacer plantearnos también qué puede llegar a sentir una celebridad ante la miríada de cuentas de usuario que han usado su nombre, su imagen, en cualquier red social. ¿Qué objetivos hay tras una acción como esta? La cuenta de Orquida desapareció al día siguiente de que Clark comentara el suceso. "Creo que con un Ben Clark ya tenemos todos bastante". No hay duda de que conseguir suplantar a una persona es esencialmente fácil. En este caso tenemos la respuesta a la pregunta que nos planteábamos antes a través de un artículo de Villa María Vivo! del mismo 24 de septiembre en el que se denunciaba la creación de perfiles falsos a partir de fotos de distintos usuarios de redes sociales para dinamizar los comentarios de una publicación en línea argentina para verter opiniones sobre política local del país:

Esta cuentas son falsas, ya que en realidad están armadas utilizando para ello fotos que pertenecen a otras personas [...].Todas las fotos que figuran de perfil o de portada como si fueran propias, en realidad son de Ben Clark, un reconocido escritor nacido en Ibiza, de familia británica, nacido el 21 de junio de 1984. Tiene su propio perfil de Facebook donde aparecen muchas de las fotos tomadas para crear el perfil "trucho" del supuesto "Orquida", junto a otras aparecidas en publicaciones periodísticas en Internet. (VILLA MARÍA VIVO!, 2014, n.p.)

El doppelgänger de Clark tenía un objetivo, por tanto, mundano y directo: favorecer a un político y una ideología concreta con los clásicos recursos de falta de 
honestidad de la profesión. Esta simpleza motivacional (si es que solo hubiere esa) contrasta con la complejidad de las acciones de Debbie y de otros personajes del panorama catfish, pero no deja de ser habitual: el spam y los intentos de inclinar la opinión del público a través de la asimilación de los discursos llanos (esto es, por ejemplo, los publicistas que simulan ser usuarios comunes en un foro o los blogs patrocinados por empresas que pretenden ser de usuarios del pueblo) se han convertido ya en algo común como parte de las estrategias de creación de opinión.

Las relaciones que se mantienen en esa esfera de virtualidad (virtual en tanto en cuanto es digital pero también en la medida en que las personas que interaccionan entre sí no son, como Kaycee, estrictamente reales) puede tener una suficiente fuerza emocional sustitutiva. Wallace ya señaló la capacidad emocional-sustitutoria de la visión de la realidad ( $y$, sobre todo, de las personas) a través de una vía comunicativa unidireccional como la televisión. Si bien es cierto que la comunicación en internet (mediante chats, videojuegos, etc.) es pluridireccional, la distancia escénica que supone la pantalla es un fuerte matizador y elemento distanciador. Pero también puede ser excesivamente acaparador en su poder sustitutorio y suplantador. Decía Wallace:

It's true that lonely people find in television's 2-D images relief from their stressful reluctance to be around human beings, then it's also obvious that the more time spent at home alone watching TV, the less time spent in the world of real human world, the harder it becomes not to feel inadequate to the tasks involved in being a part of the world, thus fundamentally apart from it, alienated from it, solipsistic, lonely. It's also true that to the extent one begins to view pseudo-relationships with Bud Bundy or Jane Pauley as acceptable alternatives to relationships with real people, one will have commensurately less conscious incentive even to try to connect with real 3-D persons, connections that seem pretty important to basic mental health. (1993, n.p.)

Luego la cuestión es hasta qué punto son reales las personas (las personalidades) con las que se establecen las relaciones virtuales en la pantalla y si son realmente sustitutorias por su poder demiúrgico de las reales. Son simulaciones de personas, con independencia de si tras ellas hay o no personas que se correspondan con la entidad percibida a través de la red. Hay quien suple ciertas necesidades sociales positivamente, como Jason Rowe a través del videojuego Star Wars Galaxies (cuyo caso expondremos a 
continuación), y quien entra en un juego de suplantación que puede afectar a terceras personas mientras persigue un beneficio que puede tener objetivos emocionales 0 económicos, por sugerir algunas motivaciones fáciles de comprender por la mayoría de las personas y que se retratan en cintas como Identity Theft: The Michelle Brown Story (2004), que adapta el caso real de Brown (a quien robaron la identidad y consiguieron realizar compras por valor de más de 50000 dólares). Kaycee, el personaje de Rowe, etc., son nuevas entidades sociales completas en el entorno digital, nuevos mianzis ${ }^{\S \S}$ porque han construido ya no solo nuevos rostros, sino entes completos aunque virtuales.

\section{Selfie de otro}

La identidad digital se construye a través de recursos que no precisan de los anclajes de lo real. Esto es algo que se supo muy pronto dentro de la historia de las tecnologías de la comunicación y que visibilizó para todo el mundo la viñeta de Peter Steiner publicada en The New Yorker el 5 de julio de 1993 titulada "On the Internet, nobody knows you're a dog". En internet —en cualquier entorno virtual, socialmente real o simulado, es decir, en una red social o en un videojuego enteramente ficcional- los recursos de construcción de identidad son amplios y la producción de presencia se puede controlar conscientemente. Los elementos de identificación pueden ser reales o impostados; se puede utilizar cualquier nombre, cualquier imagen como icono que nos represente, etc., para ser otra persona. A través de un videojuego se puede ser tanto un ogro espacial como una arqueóloga aventurera. Se puede ser cualquier persona o cosa, así que para qué ser uno mismo.

Los protocolos de identidad y cortesía en los mundos sintéticos no son los mismos que en el mundo real porque no se establecen contactos directos, cara a cara, donde la identidad propia es difícilmente falseable. En un chat, en un juego masivo o en una red

\footnotetext{
§§ El mianzi (面子) es el prestigio social del individuo según la cultura china; su importancia es vital, puesto que la percepción que se tenga de nosotros en nuestro entorno de relaciones personales o profesionales. En nuestra tradición occidental reciente (más allá de los valores históricos de honor y honra), la pieza teatral de Arthur Miller The Crucible (1953) es una muestra de la importancia de la identidad social vinculada no tanto al rostro, como al nombre mismo: Proctor rechaza firmar la falsa confesión porque su nombre es lo único que realmente posee y no puede embrutecerlo, esto es, negarse a sí mismo.
} 
social podemos convertir nuestro ciberespacio en el de otro yo. En el libro Alter Ego. Avatars and their creators (COOPER et al, 2007) se compilan múltiples testimonios de aficionados a los videojuegos. Su puesta en página destaca por presentar dos fotografías: la de la persona y la de su avatar, su personaje en el videojuego. Resulta particularmente significativo el caso de Jason Rowe, joven estadounidense nacido en 1975 en EE. UU. y aficionado al videojuego Star Wars Galaxies con un personaje que creó en 2003 bajo el seudónimo de Rurouni Kenshin en el servidor Radiant. En el retrato de Rowe vemos a un joven de aspecto débil que precisa de un respirador — padece distrofia muscular de Duchenne-y él mismo explica que:

The difference between me and my online character is pretty obvious. I have a lot of physical disabilities in real life, but in Star Wars Galaxies I can ride an Imperial speeder bike, fight monsters, or just hang out with friends at a bar. I have some use of my hands — not much, but a little. In the game I use an on-screen keyboard called "soft-type" to talk with other players. I can't press the keys on a regular keyboard so I use a virtual one. I play online games because I get to interact with people. The computer screen is my window to the world. Online it doesn't matter what you look like. Virtual worlds bring people together - everyone is on common ground. In the real world, people can be uncomfortable around me before they get to know me and realize that, apart from my outer appearance, I'm just like them. Online you get to know the person behind the keyboard before you know the physical person. The internet eliminates how you look in real life, so you get to know a person by their mind and personality. (Citado por COOPER et al, 2007, p. 23)

El control de la presencia, en este caso comprendida como la identidad física, es lo que permite a Rowe normalizar sus relaciones sociales, precisamente porque la ventana al mundo que es internet le permite también poner una cortina. De esconder o disimular el aspecto físico a hacer lo propio con la personalidad solo hay un paso: comportamientos socialmente condenados se dan a diario en internet gracias al anonimato. Esta máscara es la que permite que, tras el avatar, se realicen comentarios crueles, amenazas y, en definitiva, se sea un trol digital. Sin caer en los fantasmas neoluditas, este anonimato es lo que facilita también que se entre en contacto con personas para realizar actividades ilegales o compartir ensoñaciones vinculadas a las mismas. Tanto si son fantasías como actos reales, la máscara digital permite esconder quién se es, dificulta dejar pistas que 
identifiquen al usuario (pues incluso las direcciones IP sobre las que se sustenta toda conexión a internet pueden disimularse) y encontrar otras personas con las que realizar esas actividades o soñar con ellas colectivamente. Por supuesto, eso es una parte del espectro, pues está también la contraria: la exaltación egotista del individuo en la red social. Los espacios 2.0 de la red favorecen que el usuario se sienta el centro efectivo de un ecosistema de contactos, que tiene su plasmación estética en la autofoto o selfie. La cultura del selfie es una de las estrategias de revulsión de la estética del yo narrativizado, idealizado o ficcionalizado, en la que el individuo se convierte en eje principal de su propia narrativización, tal y como sucede en tantas redes sociales: no se basan tanto en la conexión rizomática de individuos y sociedades, sino en la construcción de sistemas (en apariencia para sus usuarios) egocéntricos en los que cada usuario es su propio Sol y el resto de entidades orbitan en torno a su campo gravitatorio.

La vida digital es, en sí misma, el espacio del semionauta, un acto de una apropiación en el que se recaptura la presencia digital para ser quien se quiere ser en la proyección y la propiocepción que se transpira. Para Bourriaud el semionauta es alguien que proyecta su propia cultura como si esta fuera el lienzo mismo sobre el que trabaja y lo modifica para crear algo nuevo a partir de la remezcla. Como ejemplificó Bourriaud, todo opera de la misma manera en la que un DJ crea nueva música uniendo fragmentos de piezas preexistentes al establecer nuevas relaciones entre esos elementos artísticos. "The Internet user may create his or her own site or homepage and constantly reshuffle the information obtained, inventing paths that can be bookmarked and reproduced at will” (BOURRIAUD, 2002, p. 18), pero quien crea una web como un jockey puede también crear una alteridad existencial en la red, un trasvase de imposturas que operan sobre la(s) vida(s) narrativizada(s). Lo que se hace en tal caso es lo mismo que describe Eugenio Tisselli en el cuarto punto de Manifiesto Text Jockey: "atreverse a interpretar 'aquello-quenos-está-sucediendo-ahora', rehabi(li)tar el texto. Ni el mundo ni la vida son libros, son texto en movimiento y transformación continua".

La vida pública, extimizada, implica una reconstrucción de la privacidad como propiedad, esto es, la socialización plena del yo y, con él, de los valores económicos del mismo a favor de un nosotros de tendencia utópica. Si equiparamos el yo con la 
propiedad privada clásica, la posmodernidad la disuelve en términos similares a los que plantearon Hardt y Negri en cuanto al capital (2000, p. 325). Pero esto es solo la mitad de la historia, la de la glorificación del nosotros: aunque la extimidad implica una mayor sociabilidad y puede asociarse a los conceptos comunitarios de disolución de la privacidad, de la propiedad (no necesariamente solo intelectual), etc., ya hemos visto en múltiples ocasiones que hay un fuerte componente egotista. Ese impulso al nosotros se sustenta realmente en la alimentación —o el cebo- del yo. Muchos yos no forman un nosotros, aunque quizá sí una ilusión del mismo, un nuevo retrato que puede (auto)convencer y convertir la narrativa del yo tanto en la exposición autobiográfica, como en la autoficcional como en la ficcional plena empleando los mismos recursos, herramientas y procesos: en la digitalidad todas estas entidades se construyen sobre los mismos pilares y la intencionalidad de su responsable tras las pantallas determinará el nivel de veracidad y ficcionalidad que quiere inyectar a sus representaciones virtuales.

El yo contemporáneo, el que vive entre lo real y lo virtual, somete su proceso vital a una mediamorfosis en la medida en que esta se reconvierte desde lo experimentado hasta lo narrativizado en una serie de procesos deformantes hipermediados. Es decir, de lo vivido a lo que se cuenta que se ha vivido hay siempre un distanciamiento que va más allá de la propia experiencia subjetivizadora del punto de vista propio. Las dulcificaciones, ilusiones, prejuicios, etc., operan sobre la construcción del relato vital y tanto la inmediatez de la narración como la demora implican puntos de vista diferentes, alteradores de lo objetivizable. La intencionalidad del narrador pesa sobre lo que se cuenta y los condicionantes de mediación (por ejemplo, qué plataforma social se emplea para contarlo) son elemento de cambio. Ir a un concierto no se puede (ni debe) contar igual en un estado de Facebook, en un tuit, en una serie de fotos en Instagram o en un vídeo en YouTube. La composición textual y audiovisual altera el relato de lo vivido y, por tanto, la memorabilia digital de la experiencia. 


\section{Referencias}

BOURRIAUD, Nicolas. Postproduction. Cultura as screenplay: How art reprograms the world. Nueva York: Lukas \& Sterling, 2002, 2005.

CARRÈRE, Emmanuel. L’adversaire. París: P.O.L., 2000.

CATFISH. Dirección de Henry Joot y Ariel Schulman. EE. UU.: Supermarché, 2010. DVD. Color. $87 \mathrm{~min}$.

CERVAS, Javier. El impostor. Barcelona: Penguin Random House, 2014.

CLARK, Ben. Hay un tal diego Orquida. Facebook, 24 de septiembre de 2014, disponible en <https://www.facebook.com/correoclark/posts/10152383480612503>. Accedido en: 20 de marzo de 2015.

COOPER, R.; DIBBELL, J.; SPAIGHT, T. Alter Ego. Avatars and their creators. Londres: Chris Boot.

DÉBORD, Guy. La sociedad del espectáculo [trad. Rodrigo Vicuña Navarro]. Santiago de Chile: Ediciones Naufragio, 1967, 1995.

DOSTOIEVSKI, Fiódor. El doble: Dos versiones: 1846 y 1866 [trad. Alejandro Ariel González]. Buenos Aires: Eterna Cadencia Editora, 2014.

EBERT, Roger. Review: Catfish. RogerEbert.com, 22 de septiembre de 2010, disponible en: <http://www.rogerebert.com/reviews/catfish-2010>. Accedido en: 20 de marzo de 2015.

EFE. El presidente de los deportados españoles en Mauthausen confiesa que nunca fue preso de los nazis. 20 Minutos, 11 de mayo de 2005, disponible en: <http://www.20minutos.es/noticia/22947/o/Mauthausen/deportados/espanoles/>. Accedido en: 20 de marzo de 2015.

ENEMY. Dirección de Denis Villeneuve. Canadá / España: Pathé International, 2013. Blu-ray. Color. $90 \mathrm{~min}$.

ENRICMARCOBTLLE [hoax]. En estos momentos dificiles. Twitter, 2 de enero de 2014, disponible en <https://twitter.com/enricmarcobtlle/status/418863824918560768>. Accedido en: 20 de marzo de 2015.

ESCANDELL MONTIEL, Daniel. Mi avatar no me comprende. Salamanca: Delirio, 2015. 
FISCHER, R. G.; GUGLIELMO, A. J. The Woman Who Wasn't There: The True Story of an Incredible Deception. Nueva York: Touchstone, 2012.

GARBO, EL ESPÍA. Dirección de Edmon Roch. España: Ikiru Films, 2009. DVD. Blanco y Negro / Color. 93 min.

HARDT, M.; NEGRI, A. Imperio. Barcelona: Paidós, 2000, 2005.

HARRIS, Tomás. Garbo: Agente doble. Madrid: Martínez Roca, 2000, 2004.

HIGH ANXIETY. Dirección de Mel Brooks. EE. UU.: 20th Century Fox, 1977. DVD. Color. 94 $\min$.

HUTCHESON, Scott. CATFISH: Real or Fake? It's a fake... sort of. Very Aware, 17 de septiembre de 2010, disponible en <http://veryaware.com/2010/09/catfish-real-or-fake-itsa-fake-sort-of/>. Accedido en: 20 de marzo de 2015.

ICH BIN ENRIC MARCO. Dirección de Santiago Fillol y Lucas Vermal. España: Corte y Confección de películas, 2009. HDV 1080i50. Color. $100 \mathrm{~min}$.

IDENTITY THEFT: THE MICHELLE BROWN STORY. Dirección de Robert Dornhelm. Canadá / EE.UU.: Alberta Film Entertainment, 2004. TV. Color. 120 min.

INLAND EMPIRE. Dirección de David Lynch. EE. UU.: StudioCanal, 2006. DVD. Colro. 197 $\min$.

L'ADVERSAIRE. Dirección de Nicole Garcia. Francia: Les Films Alain Sarde / Vertigo Films, 2002. DVD. Color. 129 min.

LA VIDA DE NADIE. Dirección de Eduard Cortés. España: Sogepaq, 2002. DVD. Color. 103 $\min$.

LECOUTEUX, Claude. Hadas, brujas y hombres lobo en la Edad Media. Historia del doble. Barcelona: José J. de Olañeta Editor, 1992, 1999.

LEHANE, Dennis. Shutter Island. Nueva York: William Morrow, 2003.

LUCA DE TENA, Torcuato. Los renglones torcidos de Dios. Barcelona: Planeta, 1979, 1998.

LUTES, Alicia. Is "Catfish" Catfishing America? Hollywood.com, 19 de febrero de 2012, disponible en <http://www.hollywood.com/news/tv/55001491/catfish-mtv-catfishingamerica>. Accedido en: 20 de marzo de 2015. 
MILLER, Arthur. The Crucible. Londres: Penguin Books, 1953, 2003.

NATIONAL GEOGRAPHIC. Tania Head, la mayor mentira del 11S. National Geographic, septiembre de 2012, disponible en: <http://www.nationalgeographic.es/noticias/nationalgeographic-channel/alicia-esteve-la-mayor-mentira-del-11s>. Accedido en: 20 de marzo de 2015.

PORTER, Rick. Catfish: The TV Show: MTV delves into online relationships. Zapzit, 3 de agosto de 2012, disponible en

<http://www.zap2it.com/blogs/catfish_the_tv_show_mtv_delves_into_online_relationshi ps-2012-08>. Accedido en: 20 de marzo de 2015.

PRIETO, Carlos. La araña que escapó de la cabeza de José Saramago. El Confidencial, 28 de marzo de 2014, disponible en: <http://www.elconfidencial.com/cultura/2014-03-28/laarana-que-escapo-de-la-cabeza-de-jose-saramago_108017/>. Accedido en: 20 de marzo de 2015.

REALITY SHOW. Catfish: The TV Show, EE. UU.: MTV, 2012-2015. Programa de TV.

SARAMAGO, José. El hombre duplicado [trad. Pilar del Río. Madrid: Santillana, 2002, 2010.

STEINER, Peter. On the Internet, nobody know you're a dog. New Yorker, 5 de julio de 1993, disponible en

<http://en.wikipedia.org/wiki/On_the_Internet,_nobody_knows_you\%27re_a_dog\#/media /File:Internet_dog.jpg>. Accedido en: 20 de marzo de 2015.

THE DOUBLE. Dirección de Richard Ayoade. Reino Unido: Alcove Entertainment, 2013. Bluray. Color. 93 min.

THE IMPOSTER. Dirección de Bart Layton. Reino Unido: 24 Seven Productions, 2012. DVD. Color. $99 \mathrm{~min}$.

THE WOMAN WHO WASN'T THERE Dirección de Angelo Guglielmo. EE.UU.: Meredith Viera Productions, 2012. iTunes. Color. $65 \mathrm{~min}$.

TISSELLI, Eugenio. TEXT JOCKEY - - MANIFIESTO. Motorhueso, 2002, disponible en: <http://motorhueso.net/textjockey.htm>. Accedido en: 20 de marzo de 2015.

VILLA MARÍA VIVO (REDACCIÓN). Usan perfiles falsos de Facebook para opinar de política local. Villa María Vivo, 24 de septiembre de 2014, disponible en <http://villamariavivo.com/?p=11902>. Accedido en: 20 de marzo de 2015. 
WALLACE, David Foster. E Unibus Pluram: Television and U.S. Fiction. En: WALLACE, D.F. A supposedly fun thing l'll never do again. Nueva York: Back Day Books, 1993, 2009. Ebook (n.p.).

Recebido em 07/05/2015 Aprovado em 30/06/2015

Universidade do Estado de Santa Catarina - UDESC Programa de Pós-Graduação em História - PPGH

Revista Tempo e Argumento Volume 07 - Número 15 - Ano 2015 tempoeargumento@gmail.com 